ARTICLE

Received 7 Jun 2014 | Accepted 17 Dec 2014 | Published 5 Feb $2015 \quad$ DOl: 10.1038/ncomms7124

\title{
Encapsulated liquid sorbents for carbon dioxide capture
}

John J. Vericella ${ }^{1,2, \star}$, Sarah E. Baker ${ }^{1, \star}$, Joshuah K. Stolaroff ${ }^{1, \star}$, Eric B. Duoss ${ }^{1, \star}$, James O. Hardin IV ${ }^{2,3,4}$, James Lewicki ${ }^{1}$, Elizabeth Glogowski ${ }^{2} \dagger$, William C. Floyd ${ }^{1}$, Carlos A. Valdez ${ }^{1}$, William L. Smith ${ }^{1,2}$, Joe H. Satcher Jr. ${ }^{1}$, William L. Bourcier ${ }^{1}$, Christopher M. Spadaccini ${ }^{1}$, Jennifer A. Lewis ${ }^{2,3,4}$ \& Roger D. Aines ${ }^{1}$

Drawbacks of current carbon dioxide capture methods include corrosivity, evaporative losses and fouling. Separating the capture solvent from infrastructure and effluent gases via microencapsulation provides possible solutions to these issues. Here we report carbon capture materials that may enable low-cost and energy-efficient capture of carbon dioxide from flue gas. Polymer microcapsules composed of liquid carbonate cores and highly permeable silicone shells are produced by microfluidic assembly. This motif couples the capacity and selectivity of liquid sorbents with high surface area to facilitate rapid and controlled carbon dioxide uptake and release over repeated cycles. While mass transport across the capsule shell is slightly lower relative to neat liquid sorbents, the surface area enhancement gained via encapsulation provides an order-of-magnitude increase in carbon dioxide absorption rates for a given sorbent mass. The microcapsules are stable under typical industrial operating conditions and may be used in supported packing and fluidized beds for large-scale carbon capture.

\footnotetext{
${ }^{1}$ Lawrence Livermore National Laboratory, Livermore, California 94551, USA. ${ }^{2}$ Materials Science and Engineering, University of Illinois at Urbana-Champaign, Urbana, Illinois 61801, USA. ${ }^{3}$ School of Engineering and Applied Sciences, Harvard University, Cambridge, Massachusetts 02138, USA. ${ }^{4}$ Wyss Institute for Biologically Inspired Engineering, Harvard University, Cambridge, Massachusetts 02138, USA. * These authors contributed equally to this work. $\dagger$ Present address: University of Wisconsin-Eau Claire, Eau Claire, Wisconsin 54702, USA. Correspondence and requests for materials should be addressed to C.M.S. (email: spadaccini2@llnl.gov) or to J.L. (email: jalewis@seas.harvard.edu) or to R.D.A. (email: aines1@llnl.gov).
} 
$\mathrm{R}$ educing carbon dioxide $\left(\mathrm{CO}_{2}\right)$ emissions from coal-fired power plants is highly desirable. However, current systems for capturing carbon from flue gas are plagued by high capital, energy and chemical costs ${ }^{1-4}$, limiting their deployment to date. The most established technique for capturing $\mathrm{CO}_{2}$ brings flue gas in contact with an aqueous amine solution, typically monoethanolamine (MEA), which reacts with $\mathrm{CO}_{2}$ to form carbamates ${ }^{5}$. While MEA has a fast absorption rate and high $\mathrm{CO}_{2}$ carrying capacity, it also possesses several drawbacks that prohibit widespread use ${ }^{6}$. MEA is highly corrosive, yields toxic degradation products, and requires significant energy to remove $\mathrm{CO}_{2}$ during sorbent regeneration ${ }^{7-11}$. To overcome these limitations, new sorbents are needed. Recently, solid sorbents with high surface areas and low $\mathrm{CO}_{2}$ binding energies, such as zeolites $^{12}$, metal-organic frameworks ${ }^{13-15}$, frustrated Lewis pairs $^{16}$ and nanoporous polymers ${ }^{17}$, have been introduced; however, they suffer from low $\mathrm{CO}_{2}$ capacity in the presence of water (which is abundant in flue gas), poor stability over multiple absorption-desorption cycles and/or high cost of production $^{5,18,19}$.

Here, we establish a new class of sorbent materials that combines the advantages of liquid solvents (that is, high capacity, high selectivity and water tolerance) and solid sorbents (for example, high surface area and low volatility). Specifically, we create highly permeable, microencapsulated carbon sorbents (MECS; Fig. 1a). During absorption, $\mathrm{CO}_{2}$ diffuses through the thin capsule shells, then dissolves and reacts in the liquid sorbent core to form the desired product(s). During regeneration, the reaction is reversed upon heating to yield high-purity $\mathrm{CO}_{2}$, which can subsequently be compressed for storage or utilization. Our core-shell MECS motif overcomes a central challenge in membrane-based gas separations ${ }^{20}$, where permeability and selectivity are often competing parameters ${ }^{21}$, since microcapsule permeability and sorbent selectivity can be independently optimized. The materials systems must meet several criteria; sorbent cores of controlled composition and geometry must be encapsulated, their polymeric shells (membranes) must be sufficiently permeable to $\mathrm{CO}_{2}$, so that the absorption rate is dominated by the encapsulated sorbent system, the sorbent system must be capable of multiple $\mathrm{CO}_{2}$ absorption-desorption cycles, and the mechanical integrity of these microcapsules must be retained during repeated cycling. After evaluating a broad range of candidate materials, we identify a silicone shell that is both photocurable and chemically compatible with the sorbent system, which is composed of either an aqueous potassium carbonate $\left(\mathrm{K}_{2} \mathrm{CO}_{3}\right)$ or sodium carbonate $\left(\mathrm{Na}_{2} \mathrm{CO}_{3}\right)$ solution (core fluid). Potassium carbonate has long been used for $\mathrm{CO}_{2}$ capture from natural gas in the Benfield Process ${ }^{22}$. More recently, carbonate solutions are being explored as an alternative to MEA for large-scale $\mathrm{CO}_{2}$ capture from power plants ${ }^{23,24}$, because they are abundant, environmentally benign, resist degradation and have low volatility. Upon solid precipitation, carbonate slurries can be regenerated at modest or high temperature $\left(80-150^{\circ} \mathrm{C}\right)$ to yield purified $\mathrm{CO}_{2}$, resulting in a more energy-efficient capture process compared with that of MEA. Importantly, the main drawbacks of carbonate sorbents, that is, their slow $\mathrm{CO}_{2}$ absorption kinetics and difficulty of handling precipitated solids in a liquid system, are overcome through encapsulation. Although corrosive or highly viscous ionic solvents may be encapsulated via the MECS motif yielding other types of capture media, we focus on carbonate solutions for this first demonstration.

\section{Results}

Microcapsule design and fabrication. Our MECS are produced using a double-capillary device ${ }^{25}$, which consists of nested glass capillaries fed by three fluids, whose flow rates are independently controlled shown in Fig. 1b. The inner fluid, that is, capsule core, is composed of an aqueous potassium or sodium carbonate solution with or without a $\mathrm{pH}$ indicator dye and catalyst for enhanced $\mathrm{CO}_{2}$ absorption. The middle fluid (capsule shell) is a photopolymerizable silicone, and the outer (carrier) fluid is composed of an aqueous solution with stabilizer and surfactant. Double emulsion droplets are produced from the device at rates of $1-100 \mathrm{~Hz}$ (Supplementary Movie 1), and subsequently cured by exposure to ultraviolet light to create microcapsules. Supplementary Fig. 1 shows a representative batch after collection and ultraviolet curing. Using this approach, we have prepared large quantities ( $>1$ litre) of MECS filled with sorbent cores ranging in concentration from 3 to $30 \%$ by weight of potassium carbonate or sodium carbonate solutions. We chose fluid viscosities, flow rates and channel sizes that enable the fabrication of nearly monodisperse microcapsules with controlled outer diameters and shell wall thicknesses ranging from 100 to $600 \mu \mathrm{m}$ and 10 to $50 \mu \mathrm{m}$, respectively.

The permeability of $\mathrm{CO}_{2}$ through the cured shell material was measured using a constant-volume, differential-pressure apparatus, in which pressure sensors on either side of the silicone membrane measure the rate of pressure change, or 'leak-up' rate, as the gas moves from the high pressure volume, through the membrane and into the low pressure volume (see Supplementary Methods). The measured $\mathrm{CO}_{2}$ permeability of the shell material is 3,260 barrer, which is quite high compared with most gas separation membranes ${ }^{20}$ and comparable to values reported for other silicones ${ }^{21}$. Notably, this material exhibits no noticeable decrease in permeability after exposure to temperatures of up to $150^{\circ} \mathrm{C}$.

The microcapsule geometries are highly uniform and can be readily adjusted by varying the fluid flow rates within the doublecapillary device. Their initial and cured dimensions are determined using image analysis (see Supplementary Methods). In Fig. 1c, optical and fluorescence microscopy images show a representative set of MECS that exhibit a highly uniform diameter $(600 \pm 6 \mu \mathrm{m})$, wall thickness $(31 \pm 1 \mu \mathrm{m})$ and centricity. Their physical dimensions can be systematically varied, as shown by the images of other representative batches with respective diameters of 185 and $600 \mu \mathrm{m}$ produced using the same device under different operating conditions (Fig. 1d, inset). Importantly, these geometries lead to a 1-2 orders of magnitude enhancement in sorbent surface area per volume of reactor relative to liquid in typical supported packing, shown in Fig. 1d (ref. 26). Although a simple packing of capsules in a tower would lead to a high pressure drop for gas flow, a supported packing that creates channels for flow or a fluidized bed would be suitable.

$\mathrm{CO}_{2}$ sorption and cycling. To enable colorimetric observation of $\mathrm{CO}_{2}$ absorption-desorption processes, we produced MECS containing a $\mathrm{pH}$ indicator dye, thymol blue, within their liquid sorbent cores. The unloaded potassium carbonate solution is blue and transforms to yellow when $90 \%$ of the maximum carbon uptake is achieved. This visible colour change serves as an effective colorimetric indicator of $\mathrm{CO}_{2}$ saturation of the liquid carbonate sorbent, enabling qualitative monitoring of capsule loading and unloading.

As a simple demonstration, we exposed MECS with liquid sorbent cores of $3 \mathrm{wt} \% \mathrm{~K}_{2} \mathrm{CO}_{3}$ and thymol blue to air and to pure $\mathrm{CO}_{2}$. This $\mathrm{K}_{2} \mathrm{CO}_{3}$ concentration is chosen to accommodate the solubility requirements of thymol blue, facilitating the colorimetric readout of capsule loading. Equilibrated in air, the microcapsules appear blue-violet. On exposure to the $\mathrm{CO}_{2}$ 
a

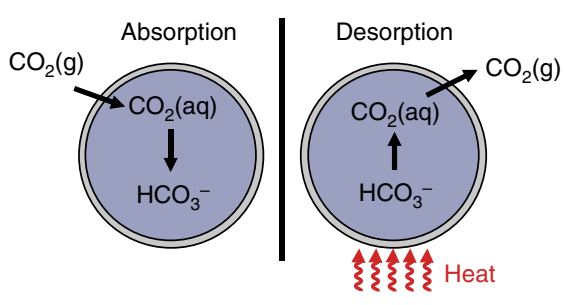

b

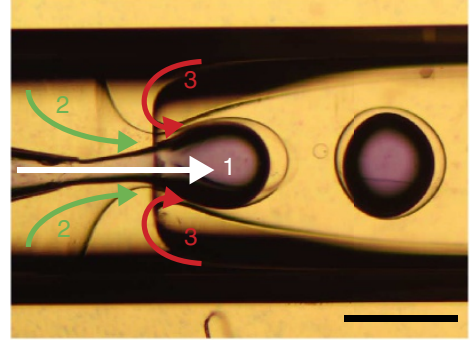

C
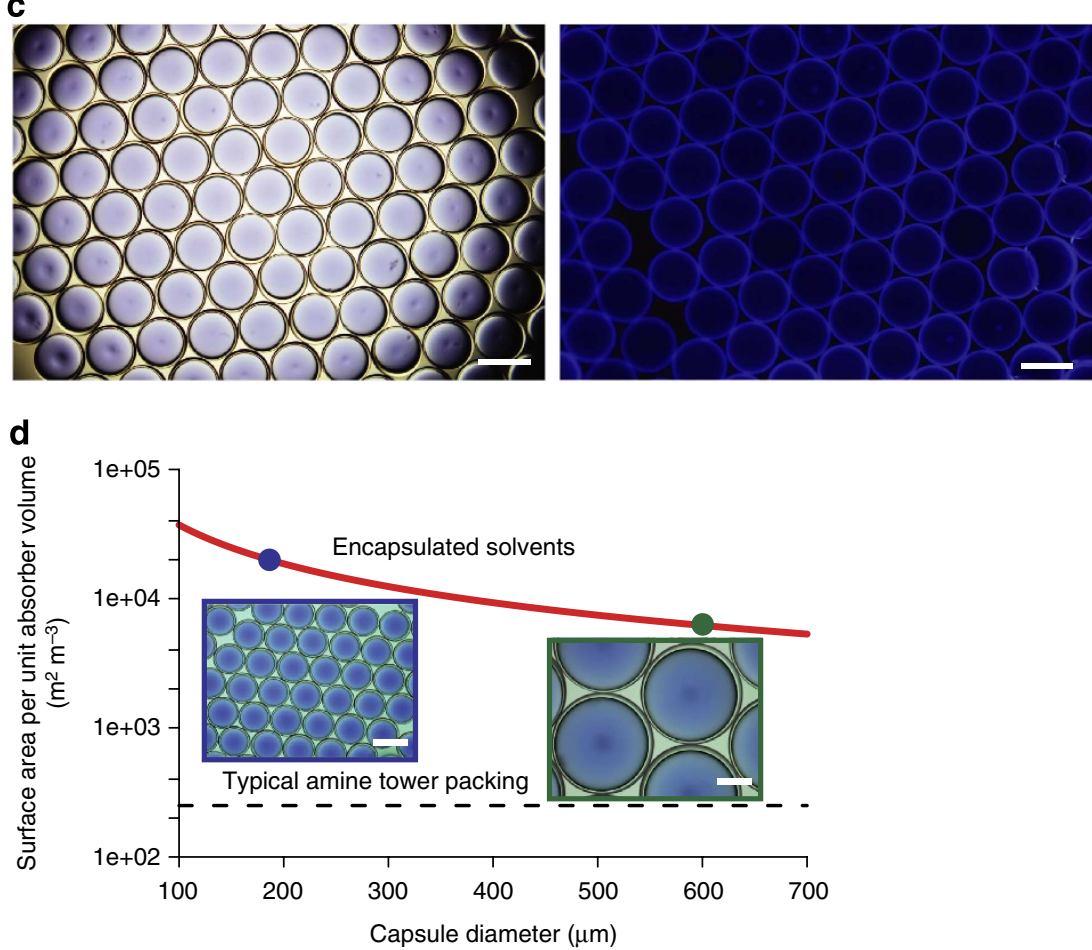

Figure 1 | Microcapsules for carbon capture. (a) Schematic illustration of the encapsulated liquid carbon capture process in which $\mathrm{CO}_{2}(\mathrm{~g})$ diffuses through a highly permeable silicone shell and is absorbed by a liquid carbonate core. The polymer microcapsules are then heated to release absorbed $\mathrm{CO}_{2}$ for subsequent collection. (b) Image of the flow-focusing microfluidic capillary device used to produce the silicone microcapsules shown in c, where fluids 1 , 2 and 3 correspond to the carbonate solution, ultraviolet-curable silicone and an outer aqueous solution, respectively. Scale bar is $250 \mu \mathrm{m}$ in length.

(c) Optical and fluorescent images of cured silicone microcapsules that possess uniform diameter $(600 \pm 6 \mu \mathrm{m})$ and wall thickness (32 $\pm 1 \mu \mathrm{m})$; scale bar, $1 \mathrm{~mm}$. (d) Semi-log plot of available solvent surface as a function of microcapsule diameter. Insets: Optical images of silicone microcapsules assembled with varying diameters of $185 \mu \mathrm{m}$ (left) and $600 \mu \mathrm{m}$ (right). Dashed line denotes available surface area estimated for traditional $\mathrm{CO}_{2}$ capture systems, in which monoethanolamine solution flows through a metal mesh-packed absorber tower. Scale bar, $\sim 200 \mu \mathrm{m}$.

atmosphere, the microcapsules quickly change to a deep, uniform yellow colour. After removing them from the $\mathrm{CO}_{2}$ atmosphere, they return to their original blue-violet shade (Fig. $2 \mathrm{a}-\mathrm{c}$ ). This approach serves as a qualitative method of evaluating the absorption and desorption of $\mathrm{CO}_{2}$ in ensembles of capsules during testing. On the basis of colorimetric analysis, their $\mathrm{pH}$ changes from $\sim 10.2$ to 9 (or lower) during $\mathrm{CO}_{2}$ absorption and returns to its original value upon desorption (shown in Supplementary Fig. 2). To complement these data, we also use a manometric method to quantify $\mathrm{CO}_{2}$ uptake. This method measures the pressure drop of $\mathrm{CO}_{2}$ in a fixed volume as $\mathrm{CO}_{2}$ is absorbed (see Methods).

Using this colorimetric method, we assessed the robustness of the microcapsule shells over multiple absorption-desorption cycles under realistic thermal cycling conditions. During cycling, polymer microcapsules are alternately exposed to $\mathrm{CO}_{2}$ bubbled through water at $20^{\circ} \mathrm{C}$ then heated to $40^{\circ} \mathrm{C}$ and $\mathrm{N}_{2}$ bubbled through water at $20^{\circ} \mathrm{C}$ then heated to $100^{\circ} \mathrm{C}$ in a custom apparatus. We monitored the colour changes and mechanical integrity via time-lapse photography over 80 cycles, and found that the colour change took place rapidly $(<1 \mathrm{~min})$ and the microcapsules not only remained intact throughout the entire testing period, but showed no apparent differences in their colorimetric response, indicating the shell material retains permeability (Supplementary Fig. 3). We found that MECS are highly permeable to water as well as $\mathrm{CO}_{2}$, and reach osmotic equilibrium with their surroundings rapidly.

Mechanical stability and crystallization. We produced MECS containing 20-30 wt\% $\mathrm{Na}_{2} \mathrm{CO}_{3}$ and tested their mechanical integrity under highly alkaline, high ionic strength conditions during precipitate formation. The $\mathrm{pH}$ profiles of $20-30 \mathrm{wt} \%$ capsules are similar to the $3 \mathrm{wt} \%$ capsules as a function of fractional loading, and the kinetics are therefore similar, although their capacities are proportionally larger, akin to those targeted 

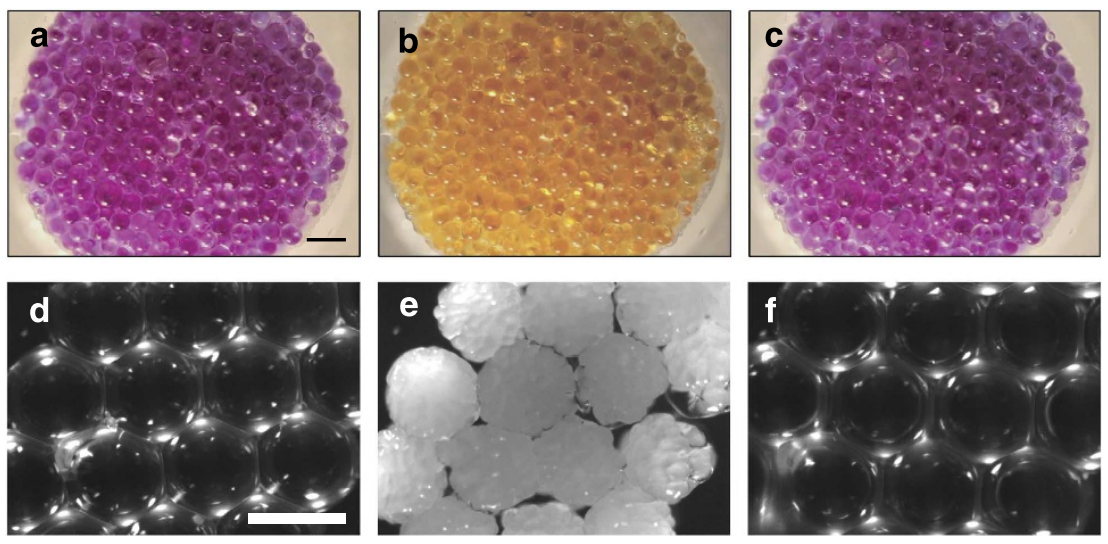

Figure $2 \mid \mathbf{C O}_{\mathbf{2}}$ sorption and cycling. (a-c) Optical images of silicone microcapsules containing 3 wt\% potassium carbonate dyed with thymol blue in air (a), after incubation in $\mathrm{CO}_{2}$ gas (b) and then after regeneration in air (c). Scale bar, $1 \mathrm{~mm}$. (d-f) Dark-field optical images of silicone microcapsules containing $30 \mathrm{wt} \%$ sodium carbonate in air (d), which were exposed to $\mathrm{CO}_{2}$ gas until precipitation of bicarbonate from solution (e), and then regenerated by heating at $70{ }^{\circ} \mathrm{C}$ to release $\mathrm{CO}_{2}$ gas and dissolve the precipitate (f). These microcapsules are mechanically robust, enabling repeated cycling of $\mathrm{CO}_{2}$ capture and regeneration without degradation of the silicone shell walls. Scale bar, $500 \mu \mathrm{m}$

for industrial use. We find that the $30 \mathrm{wt} \%$ MECS can withstand a fourfold increase in their diameter without rupture by osmotically swelling in pure water (Supplementary Fig. 4). Notably, this volumetric increase is far higher than that expected during their actual use as carbon capture media, where they will be held at osmotic equilibrium during storage. On exposure to a pure $\mathrm{CO}_{2}$ atmosphere, we observe precipitate formation within their sorbent-filled cores as shown in Fig. 2d-f and Supplementary Movie 2. These solid crystallites, confirmed by X-ray diffraction to be Nahcolite $\left(\mathrm{NaHCO}_{3}\right)$ (Supplementary Fig. 5), enable enhanced carrying capacity and are thus beneficial for $\mathrm{CO}_{2}$ capture. The solid precipitates repeatedly dissolve and reform upon cycling the microcapsules between a warm humid condition at $70{ }^{\circ} \mathrm{C}$ humidified to $\sim 60 \%$ relative humidity (in which $\mathrm{CO}_{2}$ and $\mathrm{H}_{2} \mathrm{O}$ is released) and $\mathrm{CO}_{2}$ under ambient conditions (Supplementary Fig. 6). The capacity of $30 \mathrm{wt} \% \mathrm{Na}_{2} \mathrm{CO}_{3}$ at equilibrium with flue gas with 0.1 bar $\mathrm{CO}_{2}$ partial pressure allowing for the precipitation of $\mathrm{NaHCO}_{3}(\mathrm{~s})$ calculated to be $0.10 \mathrm{~g} \mathrm{CO}_{2}$ per gram solvent, as determined by Pitzer's equations and GWB Software (see Supplementary Methods) ${ }^{27}$, the same as $\mathrm{MEA}^{28}$. On the basis of previous analysis, the working capacity of sodium carbonate solution is slightly higher than MEA (7.1 versus $6.9 \%$ g per gram $)^{29,30}$, but the values depend on process conditions. The shell material, whose thickness can be controlled, reduces the mass-basis working capacity of MECS. Compared with solid sorbents, sodium carbonate-filled MECS have capacities that are higher than hydrotalcites, similar to activated carbons, and lower than many zeolites (however, unlike most zeolites, their capacity is retained under humid conditions $)^{5}$.

The microcapsules remained mechanically stable even after cycling between air and pure $\mathrm{CO}_{2}$ multiple times. Next, we analysed the amount of $\mathrm{CO}_{2}$ released from these microcapsules during thermal desorption at 80 and $120^{\circ} \mathrm{C}$ using pyrolysis-gas chromatography/mass spectrometry. These measurements revealed that only $\mathrm{CO}_{2}$ and $\mathrm{H}_{2} \mathrm{O}$ evolve from the microcapsules at the two temperatures tested, indicating no degradation of the silicone material and release of a negligible fraction of other entrained gases. Accordingly, we calculate that in flue gas conditions, the quantity of dissolved $\mathrm{O}_{2}$ and $\mathrm{N}_{2}$ is about 10,000 times lower than that of absorbed $\mathrm{CO}_{2} . \mathrm{N}_{2}$ and $\mathrm{O}_{2}$ entrained in the shells and void spaces are expected to be similarly negligible. Overall, the selectivity of MECS for $\mathrm{CO}_{2}$ is excellent compared with membranes and solid sorbents and comparable to liquid solvents. Like liquid solvents, MECS are expected to irreversibly bind $\mathrm{SO}_{x}$ and $\mathrm{NO}_{x}$, but this has not yet been tested. The amount of $\mathrm{CO}_{2}$ produced was $\sim 0.90 \mathrm{mmolg}^{-1}$ of capsules and $2.2 \mathrm{mmolg}^{-1}$ of capsules at 80 and $120^{\circ} \mathrm{C}$, corresponding to 4.0 and $9.7 \% \mathrm{w} / \mathrm{w}$, respectively.

To explore the feasibility of MECS-based fluidized beds, we placed representative capsules containing $3 \mathrm{wt} \%$ potassium carbonate and thymol blue in a modified test tube. The capsules are first fluidized using $\mathrm{N}_{2}$ gas, at a superficial velocity on the order of $1 \mathrm{~m} \mathrm{~s}^{-1}$, which is in the range of velocities used in commercial fluidized beds ${ }^{31}$. The source gas is switched to pure $\mathrm{CO}_{2}$ gas at equivalent velocity to the $\mathrm{N}_{2}$ stream (Supplementary Movie 3). We observed that the capsules change from blue to yellow in the presence of $\mathrm{CO}_{2}$. When the gas source is switched back to $\mathrm{N}_{2}$, their colour changes back to violet. This simple demonstration suggests that fluidized bed systems will provide an effective platform for carbon capture using MECS, since the capsules can survive rigorous agitation while functioning as effective carbon capture media.

Enhancing capture kinetics. To enhance their $\mathrm{CO}_{2}$ capture kinetics, we produced MECS in which $\mathrm{Zn}-1,4,7,10$-tetraazacyclododecane ('cyclen') is incorporated within the capsule cores (3 wt\% potassium carbonate). Cyclen is a known mimic of the enzyme carbonic anhydrase and catalyses $\mathrm{CO}_{2}$ absorption into aqueous solution ${ }^{32}$. We find that cyclen significantly increases the $\mathrm{CO}_{2}$ absorption rates in carbonate solvents and remains stable at temperatures required for capsule regeneration. To monitor the effects of a catalysed liquid core, we placed MECS containing cyclen side-by-side with uncatalyzed MECS and exposed them to a $\mathrm{CO}_{2}$ atmosphere. As shown in Fig. 3c-h and Supplementary Movie 4, the catalysed microcapsules quickly absorbed $\mathrm{CO}_{2}$ and reached saturation two to three times faster than those without catalyst.

The $\mathrm{CO}_{2}$ absorption rates of MECS are measured quantitatively using a fixed-volume apparatus (see Methods). Control experiments are run with equivalent carbonate solutions in a pool of $1 \mathrm{~mm}$ depth, giving the same surface area-to-volume ratio as found for liquid solvents used in typical packed towers for $\mathrm{CO}_{2}$ absorption ${ }^{26}$. The measured (mass normalized) $\mathrm{CO}_{2}$ absorption rates for the MECS and control solutions (liquid pools) are shown in Fig. 3i. We observed a nearly 10-fold enhancement in 

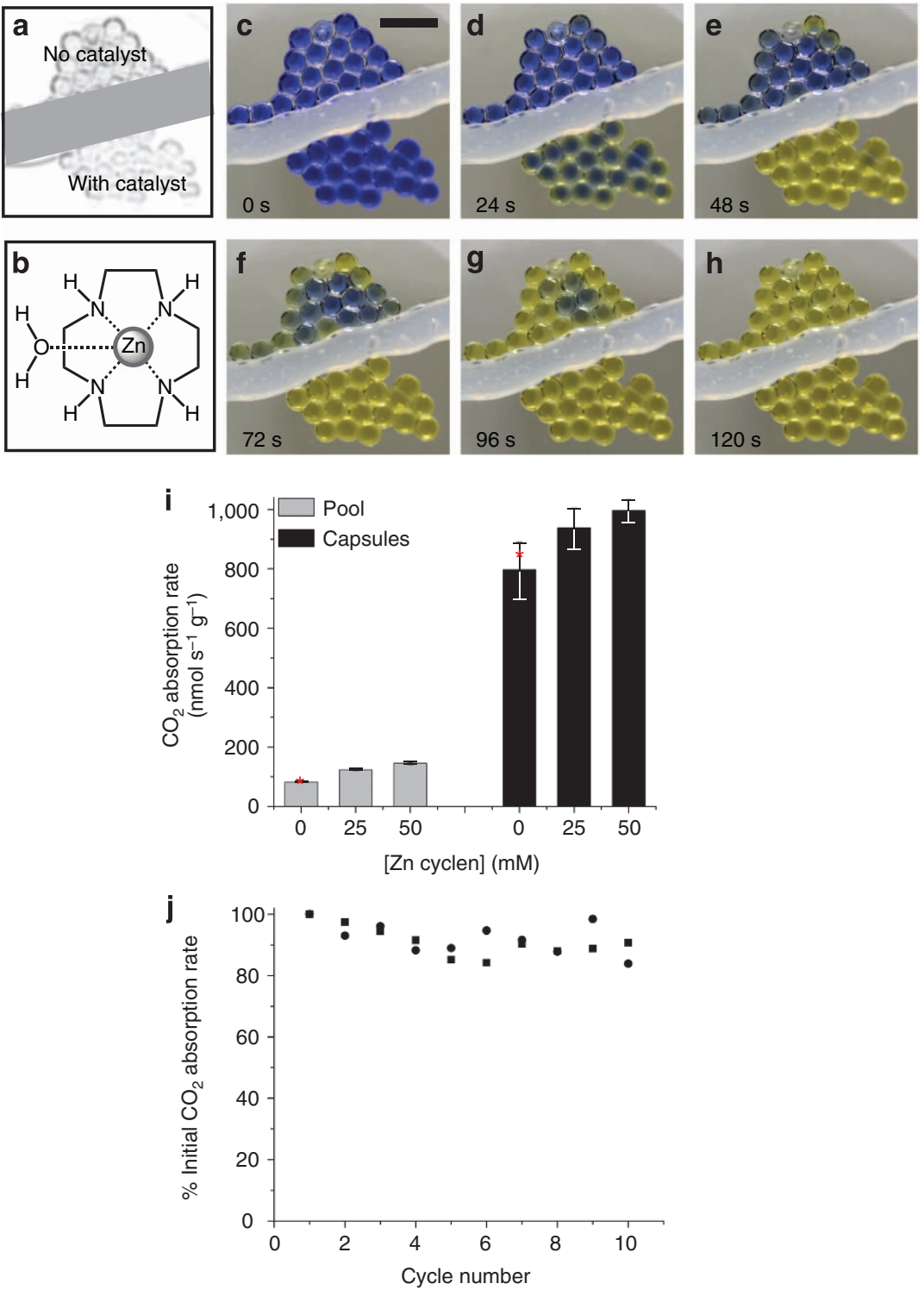

Figure 3 | Enhancing carbon capture kinetics via catalyst incorporation. (a-h) Optical images of silicone microcapsules filled with a 3 wt\% potassium carbonate solution and Thymol Blue indicator in flowing $\mathrm{CO}_{2}$ environment in the absence (top of panel) and presence (bottom of panel) of cyclen catalyst, schematically shown in $\mathbf{a}$ and $\mathbf{b}$. The microcapsules exhibit a colorimetric change in $\mathrm{pH}$ (high to low) with $\mathrm{CO}_{2}$ absorption along with an increased uptake rate in the presence of the catalyst $(\mathbf{c}-\mathbf{h})$. Scale bar, $1 \mathrm{~mm}$. (i) Plot of $\mathrm{CO}_{2}$ gas absorption rate for a liquid pool versus an encapsulated 3 wt\% potassium carbonate solution with varying catalyst concentrations. Error bars correspond to the measured standard deviation for each system. Red stars denote the analytically predicted $\mathrm{CO}_{2}$ absorption rate for the catalyst-free samples. (j) $\mathrm{CO}_{2}$ absorption rate data for the microcapsules with 50 mM catalyst included over repeated absorption of carbon dioxide after steam regeneration cycles. The different symbols indicate two separate trials with the same conditions.

absorption between these two configurations in the absence of cyclen. Further improvements (up to $12 \times$ ) in $\mathrm{CO}_{2}$ absorption rates are observed when comparing microcapsules with increasing catalyst concentrations to neat liquid sorbents of identical composition. These observations show that diffusion through the microcapsule shell is not a rate-limiting step, indicating that significant performance gains can be achieved by implementing the MECS motif. Maintaining activity over multiple absorption/desorption cycles is a necessary condition for their practical use. In addition to the 80-cycle colorimetric test described above, we directly measured MECS $\mathrm{CO}_{2}$ absorption rates over 10 absorption-desorption cycles for two sets of microcapsules Fig. 3j. We found that the MECS retained at least $90 \%$ of their initial absorption rate during this testing process. We also compared the initial and final number of total moles of $\mathrm{CO}_{2}$ absorbed per gram of capsules for the first and 10th absorption cycle, and found that capsules absorbed nearly equivalent (within $90 \%$ of initial equilibrium capacity) moles of $\mathrm{CO}_{2}$ after 10 cycles.

We compared the $\mathrm{CO}_{2}$ absorption rate measurements of uncatalyzed capsules and solutions with theoretical predictions to gain understanding of the impact of our MECS motif. The absorption rate of pure carbonate solution (pool) can be estimated by ${ }^{33}$ :

$$
\text { absorption rate }=\left.\frac{\mathrm{d} n}{\mathrm{~d} t}\right|_{\text {liquid }}=P_{\mathrm{CO}_{2}} k_{\text {solvent }} A
$$


where $A$ is the interfacial area, $P_{\mathrm{CO}_{2}}$ is the partial pressure of $\mathrm{CO}_{2}$ gas in the chamber and $k_{\text {solvent }}$ is the mass transfer coefficient of the solvent, which for carbonate solutions with low loading can be simplified to:

$$
k_{\text {solvent }}=K_{\mathrm{H}} \sqrt{D_{\mathrm{CO}_{2}} k_{\mathrm{OH}}\left[\mathrm{OH}^{-}\right]}
$$

where $K_{\mathrm{H}}$ is the Henry's constant for $\mathrm{CO}_{2}, D_{\mathrm{CO}_{2}}$ is the diffusivity of $\mathrm{CO}_{2}$ in the solvent and $k_{\mathrm{OH}}$ is the kinetic constant for reaction of $\mathrm{CO}_{2}(\mathrm{aq})$ (equation (4) in Supplementary Methods). We propose that the absorption rate of capsules can be estimated by:

$$
\left.\frac{\mathrm{d} n}{\mathrm{~d} t}\right|_{\text {capsule }}=\frac{P_{\mathrm{CO}_{2}} A k_{\text {solvent }} P_{\text {shell }}}{L k_{\text {solvent }}+P_{\text {shell }}}
$$

where $P_{\text {shell }}$ is the permeability of the shell material (in units of length ${ }^{2}$ per time), and $L$ is the thickness of the shell. Using the measured permeability along with reported values for other parameters, we calculate the absorption rates shown as stars in Fig. 3i. The measured rates for the liquid pool (control) and microcapsules are only slightly lower $(\sim 11-13 \%)$ than the calculated values; validating our approach of treating the microcapsules as a permeable membrane and solvent in series (more details are provided in Supplementary Methods). Direct comparison between capsules and liquid pools at higher sodium carbonate concentrations, where crystallization occurs, is less straightforward, because Nahcolite at the air-solution interface inhibits diffusion of $\mathrm{CO}_{2}$ into the unreacted solution.

\section{Discussion}

Silicone microcapsules filled with liquid carbonate sorbents exhibit an order-of-magnitude higher $\mathrm{CO}_{2}$ absorption rate relative to neat sorbents of equivalent mass. The good agreement between predicted and measured mass transfer rates indicates that future development of encapsulated solvents can draw on extensive research on carbon capture liquids and gas separation membranes to inform both shell material and sorbent selection. We note that additional improvements in $\mathrm{CO}_{2}$ capture rates can be achieved simply by optimizing the capsule geometry (for example, the smallest microcapsules produced have twofold higher surface area than those reported, Fig. 1d). In addition, a broader range of sorbent and catalyst chemistries can be readily explored using this facile approach to achieve tailored functionality. These microcapsules are also well suited for use in supported packing or fluidized beds, as an important embodiment in their practical deployment.

We have demonstrated a new class of hybrid liquid/solid materials that are highly permeable, mechanically robust, chemically stable and environmentally benign. Our encapsulation scheme enables the use of liquid sorbents with more favourable thermodynamics and lower environmental impact than MEA by improving mass transfer rates, containing precipitates, and isolating degradation products. A system based on concentrated sodium carbonate slurry can be run with less parasitic heating and evaporation of water than conventional amine systems and will not release toxic volatile organic compounds. Hence, microencapsulated carbon sorbents offer a promising approach for large-scale carbon capture from power plants that is both safer and more energy efficient than current alternatives.

\section{Methods}

MECS fabrication. Microcapsules are produced using a double-capillary device that consists of an outer square glass capillary, an inner circular capillary that has been flame polished and a final circular capillary that has been pulled to a fine tip. The pulled tip is drawn down using a laser tip puller to a final diameter of $30-40 \mu \mathrm{m}$. The two round capillaries are inserted into the square glass capillary. Epoxy is used to bond syringe tips to the capillaries and hermetically seal the device to the glass slide. Double emulsion droplets are produced by co-flowing three fluids in the device: (1) aqueous carbonate solution (inner fluid) for the carbon capture solvent, (2) a hydrophobic photopolymerizable silicone (middle fluid) (Semicosil 949UV, Wacker Chemie AG) for the shell material and (3) an aqueous carrier fluid with surfactant (outer fluid).

After formation, the droplets exit the device and are collected in fluid and cured under ultraviolet light $(\lambda=365 \mathrm{~nm})$. After curing, the polymerized microcapsules can be transferred and handled. After fabrication, microcapsules are stored in a potassium carbonate solution isotonic with the liquid sorbent cores to minimize osmotic swelling and rupture (Supplementary Fig. 1). When the osmotic gradient is minimized, the microcapsules are stable for years with no apparent change in size or leakage.

MECS characterization. The introduction of a $\mathrm{pH}$ indicator dye, thymol blue, into the carbonate solvent before encapsulation enables visual confirmation that $\mathrm{CO}_{2}$ is being absorbed by the encapsulated carbonate causing a $\mathrm{pH}$ swing. As the carbonate solution absorbs $\mathrm{CO}_{2}$, it reacts to form bicarbonate $\left(\mathrm{HCO}_{3}^{-}\right)$according to:

$$
\mathrm{CO}_{2}(\mathrm{aq})+\mathrm{OH}^{-} \stackrel{k_{\mathrm{OH}}}{\longrightarrow} \mathrm{HCO}_{3}^{-}
$$

while carbonate ions act as a buffer:

$$
\mathrm{CO}_{3}^{2-}+\mathrm{H}_{2} \mathrm{O} \rightarrow \mathrm{HCO}_{3}^{-}+\mathrm{OH}
$$

Before $\mathrm{CO}_{2}$ uptake, the dissolved carbon is present as carbonate $\left(\mathrm{CO}_{3}^{2-}\right)$ in the initial 'unloaded' solution. By contrast, after $\mathrm{CO}_{2}$ uptake, the carbon is present as bicarbonate leading to a reduction in the $\mathrm{pH}$ and a doubling of the initial carbon content in the fully 'loaded' solution. The calculated $\mathrm{pH}$ of the liquid sorbent core as a function of $\mathrm{CO}_{2}$ absorption along with the corresponding thymol blue colour transition is provided in Supplementary Fig. 2.

A custom testing apparatus was built to controllably and rapidly cycle capsules between different gases and temperatures. In a single cycle, the microcapsules are first exposed to humid flowing nitrogen $\left(\mathrm{N}_{2}\right)$ gas at $40^{\circ} \mathrm{C}$ to achieve temperature equilibration. Next, they are exposed to $\mathrm{CO}_{2}$ gas at $40^{\circ} \mathrm{C}$ for loading $\left(\mathrm{CO}_{2}\right.$ absorption). Finally they are exposed to $\mathrm{N}_{2}$ gas at $100^{\circ} \mathrm{C}$ for unloading (that is, $\mathrm{CO}_{2}$ desorption). This was repeated for 80 cycles.

For the fluidized bed test, capsules were first removed from the storage fluid, allowed to dry briefly in air, and then lightly powdered with potassium carbonate dust. The capsules were then loaded in a modified graduated cylinder with mesh blocking the inlets and outlets and connected to $\mathrm{N}_{2}$ and $\mathrm{CO}_{2}$ gas sources, flowing at a superficial velocity of $1.6 \mathrm{~m} \mathrm{~s}^{-1}$ for both gases. While $\mathrm{N}_{2}$ was used to allow desorption at room temperature for this proof of concept testing, an industrial process is likely to regenerate at high temperature using $\mathrm{CO}_{2}$ or a mixture of $\mathrm{CO}_{2}$ and steam as the fluidization agent.

Mass transfer measurements. Absorption isotherms (equilibrium capacity) are typically reported for new solid sorbents. However, the vapour-liquid equilibria of carbonate solutions have been investigated previously ${ }^{33,34}$, and the MECS process is not expected to change the equivalent vapour-liquid equilibria of the encapsulated solvent. By contrast, absorption kinetics may be strongly affected by encapsulation. We therefore focused on measuring the rate of absorption at relevant $\mathrm{CO}_{2}$ partial pressures.

To measure $\mathrm{CO}_{2}$ absorption kinetics, we suspended MECS on a steel mesh in a sealed, fixed-volume, temperature-controlled vacuum chamber equipped with a pressure gauge and a valve for the introduction of $\mathrm{CO}_{2}$ (Supplementary Fig. 7) ${ }^{35-37}$ Although gravimetric methods are typically used for solid sorbent investigations, that technique is complicated by water exchange in and out of the hybrid liquidsolid capsule system we investigate here. The mesh size was chosen to separate capsules from each other and maximize accessible surface area. The chamber was evacuated to the solution vapour pressure and a controlled quantity of $\mathrm{CO}_{2}$ was introduced, followed by sealing the chamber and monitoring the total pressure over time. The water vapour pressure was assumed to remain constant and was subtracted from the total to give the $\mathrm{CO}_{2}$ partial pressure. Typical raw data from this absorption measurement is shown in Supplementary Fig. 8. As shown, both the absorption kinetics and the absorption capacity of the materials can be measured as the slope of the pressure versus time trace and the difference between the starting and final $\mathrm{CO}_{2}$ partial pressures, respectively. For the control experiments, we created a small pool in the apparatus with a $1 \mathrm{~mm}$ depth, which is the average depth of solution on the packing in a typical packed tower for $\mathrm{CO}_{2}$ capture. At low loading (high $\mathrm{pH}$ ), stirring or flowing has little effect on the rate of $\mathrm{CO}_{2}$ absorption of a carbonate solution since the rate is driven by reaction. Hence, the $1 \mathrm{~mm}$ pool is a fair representation of the absorption rate in a typical tower. Because both the encapsulated liquid sorbent and pool have the same composition, a meaningful comparison of their $\mathrm{CO}_{2}$ absorption kinetics can be made. To test the kinetics and capacity of the capsules over multiple absorption-regeneration cycles, we used the sealed chamber and pressure measurement described. To regenerate the capsules after each exposure, we heated the capsules to $90^{\circ} \mathrm{C}$ in humid air for $10 \mathrm{~min}$.

Details regarding the carbonate capacity, thermodynamics and mass transfer modelling can be found in the Supplementary Methods. 


\section{References}

1. Chu, S. Carbon capture and sequestration. Science 325, 1599-1599 (2009).

2. Haszeldine, R. S. Carbon capture and storage: how green can black be? Science 325, 1647-1652 (2009).

3. Rochelle, G. T. Amine scrubbing for CO2 capture. Science 325, 1652-1654 (2009).

4. Friedlingstein, P. et al. Long-term climate implications of twenty-first century options for carbon dioxide emission mitigation. Nat. Clim. Chang. 1, 457-461 (2011).

5. Choi, S., Drese, J. H. \& Jones, C. W. Adsorbent materials for carbon dioxide capture from large anthropogenic point sources. ChemSusChem 2, 796-854 (2009).

6. Bishnoi, S. \& Rochelle, G. T. Absorption of carbon dioxide into aqueous piperazine-reaction kinetics, mass transfer and solubility. Chem. Eng. Sci. 55, 5531-5543 (2000).

7. Nielsen, C. J., Herrmann, H. \& Weller, C. Atmospheric chemistry and environmental impact of the use of amines in carbon capture and storage (CCS). Chem. Soc. Rev. 41, 6684-6704 (2012).

8. Da Silva, E. F. \& Booth, A. M. Emissions from postcombustion CO2 capture plants. Environ. Sci. Technol. 47, 659-660 (2013).

9. Voice, A. K. \& Rochelle, G. T. Products and process variables in oxidation of monoethanolamine for CO2 capture. Int. J. Greenh. Gas Con. 12, 472-477 (2013).

10. Reynolds, A. J., Verheyen, T. V., Adeloju, S. B., Meuleman, E. \& Feron, P. Towards commercial scale postcombustion capture of $\mathrm{CO} 2$ with monoethanolamine solvent: key considerations for solvent management and environmental impacts. Environ. Sci. Technol. 46, 3643-3654 (2012).

11. Lively, R. P., Chance, R. R. \& Koros, W. J. Enabling low-cost CO2 capture via heat integration. Ind. Eng. Chem. Res. 49, 7550-7562 (2010).

12. Banerjee, R. et al. High-throughput synthesis of zeolitic imidazolate frameworks and application to CO2 capture. Science 319, 939-943 (2008).

13. Britt, D., Furukawa, H., Glover, T. G. \& Yaghi, O. M. Highly efficient separation of carbon dioxide by a metal-organic framework replete with open metal sites. Proc. Natl Acad. Sci. 106, 20637-20640 (2009).

14. Farha, O. K. et al. De novo synthesis of a metal-organic framework material featuring ultrahigh surface area and gas storage capacities. Nat. Chem. 2, 944-948 (2010).

15. Xiang, S. et al. Microporous metal-organic framework with potential for carbon dioxide capture at ambient conditions. Nat. Commun. 3, 954 (2012).

16. Voicu, D. et al. Microfluidic studies of $\mathrm{CO} 2$ sequestration by frustrated Lewis pairs. J. Am. Chem. Soc. 136, 3875-3880 (2014)

17. Patel, H. A. et al. Unprecedented high-temperature CO2 selectivity in N2phobic nanoporous covalent organic polymers. Nat. Commun. 4, 1357 (2013).

18. Liu, Y. \& Wilcox, J. Molecular simulation studies of $\mathrm{CO} 2$ adsorption by carbon model compounds for carbon capture and sequestration applications. Environ. Sci. Technol. 47, 95-101 (2013).

19. Li, H., Eddaoudi, M., O'Keeffe, M. \& Yaghi, O. M. Design and synthesis of an exceptionally stable and highly porous metal-organic framework. Nature 402, 276-279 (1999).

20. Powell, C. E. \& Qiao, G. G. Polymeric CO2/N2 gas separation membranes for the capture of carbon dioxide from power plant flue gases. J. Membrane Sci. 279, 1-49 (2006).

21. Robeson, L. M. Correlation of separation factor versus permeability for polymeric membranes. J. Membrane Sci. 62, 165-185 (1991).

22. Kohl, A. \& Nielsen, R in Gas Purification 900Gulf Professional Publishing, 1997).

23. Knuutila, H., Svendsen, H. F. \& Anttila, M. CO2 capture from coal-fired power plants based on sodium carbonate slurry; a systems feasibility and sensitivity study. Int. J. Greenh. Gas Con. 3, 143-151 (2009).

24. Mehdipour, M., Karami, M. R., Keshavarz, P. \& Ayatollahi, S. Analysis of CO2 separation with aqueous potassium carbonate solution in a hollow fiber membrane contactor. Energ. Fuel. 27, 2185-2193 (2013).

25. Utada, A. S. et al. Monodisperse double emulsions generated from a microcapillary device. Science 308, 537-541 (2005).

26. Fair, J. R., Steinmeyer, D. E., Penney, W. R. \& Crocker, B. B. Chemical Engineer's Handbook (McGraw-Hill, 1997).

27. Jou, F.-Y., Mather, A. E. \& Otto, F. D. The solubility of $\mathrm{CO} 2$ in a 30 mass percent monoethanolamine solution. Can. J. Chem. Eng. 73, 140-147 (1995).

28. Aronu, U. E. et al. Solubility of CO2 in 15, 30, 45 and 60 mass\% MEA from 40 to $120^{\circ} \mathrm{C}$ and model representation using the extended UNIQUAC framework. Chem. Eng. Sci. 66, 6393-6406 (2011).
29. Ciferno, J. et al. Carbon Dioxide Capture from Existing Coal-Fired Power Plants 229 (National Energy Technology Laboratory, 2007).

30. Stolaroff, J. K. \& Bourcier, W. L. Thermodynamic assessment of microencapsulated sodium carbonate slurry for carbon capture. Energy Procedia 63, 2331-2335 (2014)

31. Pell, M. \& Dunson, J. B. in Perry's Chemical Engineers' Handbook (eds Perry, R. H. \& Green, D. W.) (McGraw-Hill, 1997).

32. Zhang, X. \& Van Eldik, R. A functional model for carbonic anhydrase: thermodynamic and kinetic study of a tetraazacyclododecane complex of zinc (II). Inorg. Chem. 34, 5606-5614 (1995).

33. Knuutila, H., Juliussen, O. \& Svendsen, H. F. Kinetics of the reaction of carbon dioxide with aqueous sodium and potassium carbonate solutions. Chem. Eng. Sci. 65, 6077-6088 (2010).

34. Knuutila, H., Hessen, E. T., Kim, I., Haug-Warberg, T. \& Svendsen, H. F. Vapor-liquid equilibrium in the sodium carbonate-sodium bicarbonate-waterCO2-system. Chem. Eng. Sci. 65, 2218-2226 (2010).

35. Zhang, S., Zhang, Z., Lu, Y., Rostam-Abadi, M. \& Jones, A. Activity and stability of immobilized carbonic anhydrase for promoting CO2 absorption into a carbonate solution for post-combustion CO2 capture. Bioresour. Technol. 102, 10194-10201 (2011).

36. Kucka, L., Richter, J., Kenig, E. Y. \& Gorak, A. Determination of gas-liquid reaction kinetics with a stirred cell reactor. Sep. Purif. Technol. 31, 163-175 (2003).

37. Roughton, F. \& Booth, V. The manometric determination of the activity of carbonic anhydrase under varied conditions. Biochem. J. 40, 308-319 (1946)

\section{Acknowledgements}

We gratefully acknowledge funding provided by Advanced Research Projects AgencyEnergy through the US Department of Energy Innovative Materials and Processes for Advanced Carbon Capture Technology (IMPACCT) Program Award 09/CJ000/05/01 (LLNL) DE-AR0000099 (University of Illinois and Babcock and Wilcox). LLNL-JRNL636834-DRAFT. We thank C. Martinez for useful discussions on droplet-based microfluidics and S. Roberts for help with collecting and analysing the X-ray diffraction spectra. J.O. Hardin was supported by an IC Postdoctoral Fellowship.

\section{Author contributions}

J.J.V. fabricated, characterized and tested the materials, analysed the data, designed the experiments and wrote the manuscript. S.E.B. characterized and tested the materials, designed the experiments, analysed the data and wrote the manuscript. J.K.S. contributed towards application expertise, experimental design, data analysis, theoretical mass transfer calculations and text throughout. E.B.D. fabricated, characterized and tested the materials, analysed the data, designed the experiments and wrote the manuscript. J.O.H. IV fabricated and characterized the materials, designed the crystallization studies and analysed the data, as well as contributed to the manuscript. J.L. performed the chromatography measurements and analysed the data. E.G. designed the experiments, contributed to the materials selection and design and interpreted the data. W.C.F and C.A.V synthesized and tested the cyclen catalyst and assisted with the interpretation of catalytic activity. W.L.S. fabricated the microfluidic devices, fabricated and characterized the materials and aided measurement experiments. W.L.B. contributed towards the chemical equilibrium calculations used throughout and the discussion of carbonate solution thermodynamics. J.H.S. Jr advised and analysed the fabrication chemistry details. C.M.S. aided the initial fabrication setups, contributed to the data analysis and discussion, materials selection, manuscript revision and project supervision. J.A.L. contributed to the experimental design and analysis and wrote the manuscript. R.D.A. and J.A.L. are the senior contributing PIs at their respective institutions.

\section{Additional information}

Supplementary Information accompanies this paper at http://www.nature.com/ naturecommunications

Competing financial interests: The authors declare no competing financial interests.

Reprints and permission information is available online at http://npg.nature.com/ reprintsandpermissions/

How to cite this article: Vericella, J. J. et al. Encapsulated liquid sorbents for carbon dioxide capture. Nat. Commun. 6:6124 doi: 10.1038/ncomms7124 (2015). 